\title{
A geodemographic analysis of the Denplan patient population in the North West Region
}

\author{
M. Tickle, ' A. S. Blinkhorn, ${ }^{2}$ P. J. B. Brown, ${ }^{3}$ and R. Matthews, ${ }^{4}$
}

Objective To provide a preliminary descriptive investigation of Denplan patients in the North West Region, by plotting the age/gender and payment banding distribution, and to identify the area types where Denplan patients live and the areas in the North West Region where Denplan practices are most likely to thrive.

Setting North West Region of England

Subjects and Materials The study included Denplan patients resident in the North West Region. Age/gender and payment banding frequency distributions were constructed. A market penetration ranking report using the Target Market level of the Super Profiles geodemographic classification was produced by a spreadsheet analysis in Microsoft Excel. A Lorenz curve was plotted to graphically represent the output of the market penetration analysis. Following the market penetration analysis the enumeration districts (EDs) of the six top ranked Target Markets in the North West Region were identified and mapped out across the Region. Finally, the number and percentage of EDs in the six top ranked Target Markets were identified for each health authority in the Region.

Results 47,106 patients were registered with Denplan. In all but one 5-year age band (16-20-year-olds) female patients were in the majority. Patients were concentrated $(40.5 \%)$ into the $40-55$ age group. Nearly $50 \%(22,329)$ of patients were allocated to the second lowest payment banding. Under $0.5 \%$ of patients $(N=199)$ were categorised into the highest payment band. The Target Markets at the top of the penetration ranking were more affluent in nature, with a strong rural element and an older demographic profile as part of their descriptive titles. At the bottom of the ranking deprived area types with young demographic profiles predominated. About one half $(49.9 \%)$ of Denplan patients were present in just over a quarter $(25.7 \%)$ of the total population of the North West Region. The Lorenz curve demonstrated that Super Profiles at Target Market level had an effectiveness of $37.9 \%$ in segmenting the population of the North West Region according to Denplan registration status. Conclusions The population using this service in the North West Region tend to be from more mature, rural and affluent

${ }^{1}$ Senior Lecturer/Consultant in Dental Public Health, University Dental Hospital of Manchester, Manchester and Salford \& Trafford Health Authorities; ${ }^{2}$ Professor of Oral Health, University Dental Hospital of Manchester, Full Address?; ${ }^{3}$ Senior Lecturer, Department of Civic Design, University of Liverpool Full Address??; ${ }^{4}$ Chief Dental Officer, Denplan, Victoria Road, Winchester, SO23 7RG Correspondence to: Martin Tickle, Manchester Health Authority, Gateway House, Piccadilly South, Manchester M60 7LP

email:Martin.Tickle@mchester-ha.nwest.nhs.uk

REFEREED PAPER

Received 7.01.00; Accepted 12.04.00

(c) British Dental Journal 2000; 189: 494-499 populations. The Super Profiles classification was moderately successful in segmenting the population of the North West Region according to their Denplan registration status

The new contract was introduced into the NHS General Dental I Service (GDS) in $1990 .{ }^{1}$ Dentists registered greater numbers of patients than predicted, resulting in a perceived overpayment of dentists by the Government, this led to the dispute of 1992 between the Government and the profession. ${ }^{2}$ Many observers see this dispute as a major catalyst to the growth of independently funded dentistry in the UK, as dentists made greater efforts to diversify their income by promoting clinical care on an independent rather than NHS basis. The NHS dental service was recently estimated to have $70 \%$ of the primary dental care market in the $\mathrm{UK}^{3}$ The remaining $30 \%$ of independent care is thought to be dominated by private fee-for-service arrangements between dentist and patient. Capitation-based schemes are also available, provided via a contract between the patient and dentist with a third-party commercial organisation acting as a business consultancy service for the general dental practitioner (GDP). Under this arrangement patients are assigned to a fee-band determined by the GDP using a weighting formula, taking into account the patient's oral health status. The third-party organisation collects the patient's monthly payment by direct debit, and after allowing for an administration fee, pays the dentist. Denplan, the market leader in this sector in the UK had in 1997 some 800,000 patients registered, and some 5,000 member dentists, making up $86 \%$ of the private payment plan market. BUPA were estimated to have 70,000 patients and 3,000 dentists, and Norwich Union less than 20,000 patients and 1,500 dentists. The independent sector also includes true insurance products confined to the business sector, with some $5 \%$ of companies believed to offer some kind of dental benefit to employees. ${ }^{4}$

At present there is little or no published work on the uptake of independently funded primary dental care in the UK. It is believed that there are large geographical differences in the provision of privately financed dental care across the country, and that GDPs moving into the independent sector have tended not to completely sever their links with the NHS, leading to a mixedmarket of care. ${ }^{5}$

Little is known about the factors that encourage or even compel patients to take up independently financed care. It is well known that demographic variables such as gender, age and socio-economic status all influence how dental services are used. ${ }^{6}$ Variables related to local geography and provision of NHS dental services are probably just as important. The retail and service industries employ modern marketing techniques to estimate who will use their services and identify where they live. Geodemographic classifications are commonly used to this end. These indicators are derived from Census data and classify small areas into a range of descriptive types. They 


\section{RESEARCH demographics} distribution of the number of Denplan capitation patients by 5-year age
Fig. I Frequency bands and gender

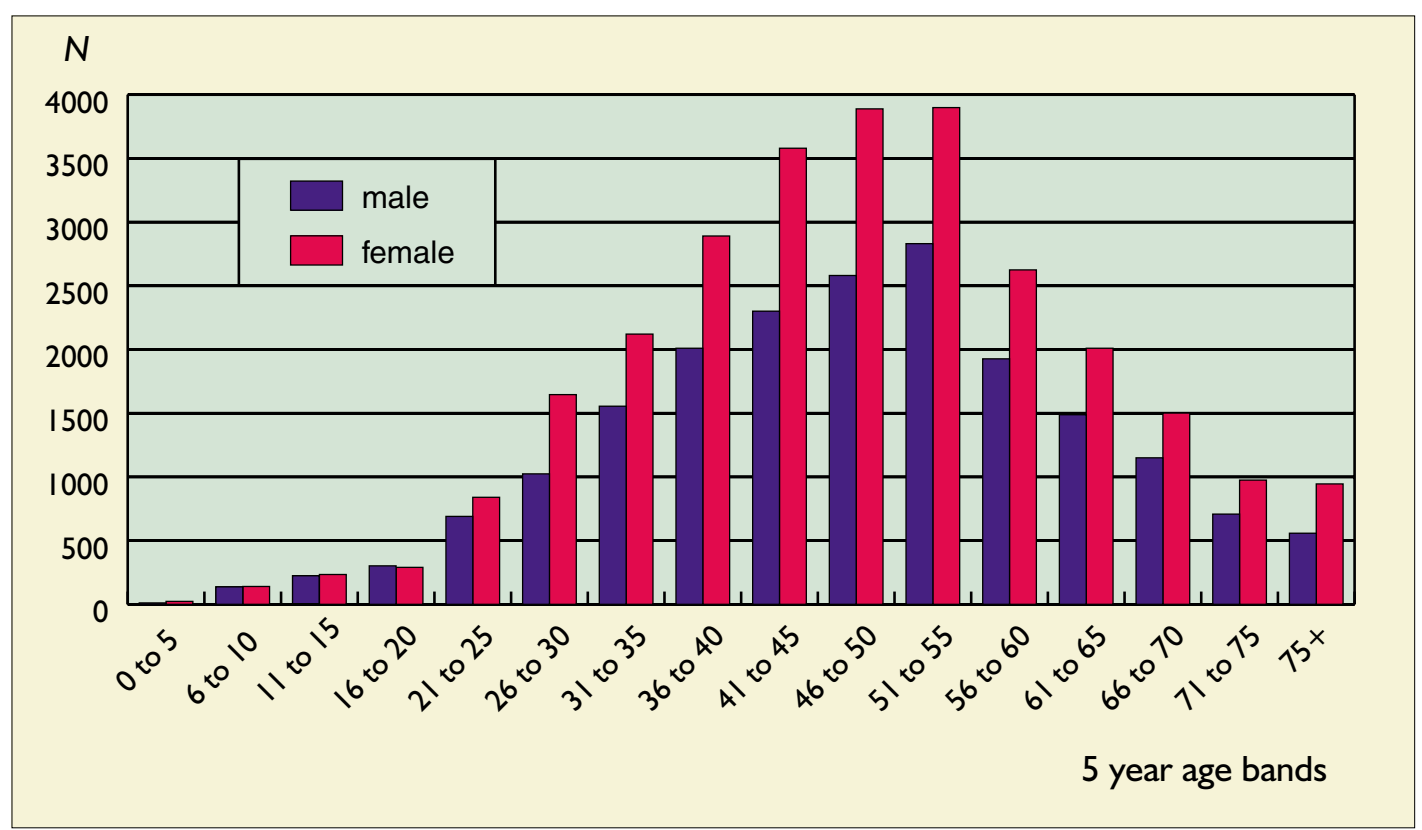

have proved to be powerful discriminators of consumer behaviour and aids to 'market analysis.'

Retail analysis makes an assumption that demand for products and services varies between different types of households and these demands are met by competing services. This application of geodemographics in retail analysis is intimately associated with Geographic Information Systems (GIS) which are computer programs that can not only draw maps but also manipulate and analyse geographically linked data. These techniques are commonly used to aid decisions on the location of new retail outlets such as supermarkets. ${ }^{7}$

This type of information would be useful to GDPs to help them make business decisions about their practice and also for the capitation companies to estimate potential demand for their services. It would also be useful to the NHS to identify areas where access to NHS services could be a problem.

The aim of this study was to provide a preliminary descriptive investigation of Denplan patients in the North West Region. More specifically the objectives were to: plot the age/gender and payment banding distribution; to geodemographically identify the area types where Denplan patients live, and the areas in the North West Region where Denplan practices are most likely to thrive.

\section{Method}

In 1998, the Denplan information department provided an anonymised file that included all patients registered with Denplan who were resident in the North West Region. This file contained the patients' postcode, gender, date of birth and the payment band in which the patient was classified. Age/gender and payment banding frequency distributions were constructed. Denplan monthly payments are split into five categories, band A represents the lowest monthly capitation payment, band $\mathrm{E}$ the highest.

The patient postcodes were used to identify the location and area type in which patients lived, a process known as georeferencing. This process attached an enumeration district (ED) code to each record. EDs are the smallest unit of the Census, each with around 120 households and a population of 400 individuals. The georeferencing process also added the relevant Super Profiles values for each ED. The Super Profiles geodemographic classification classifies every ED in England, Scotland and Wales based upon data derived from the 1991 Census. ${ }^{8}$

The 40-group Target Market level ${ }^{9}$ of the classification was used to segment the population of the North West Region according to

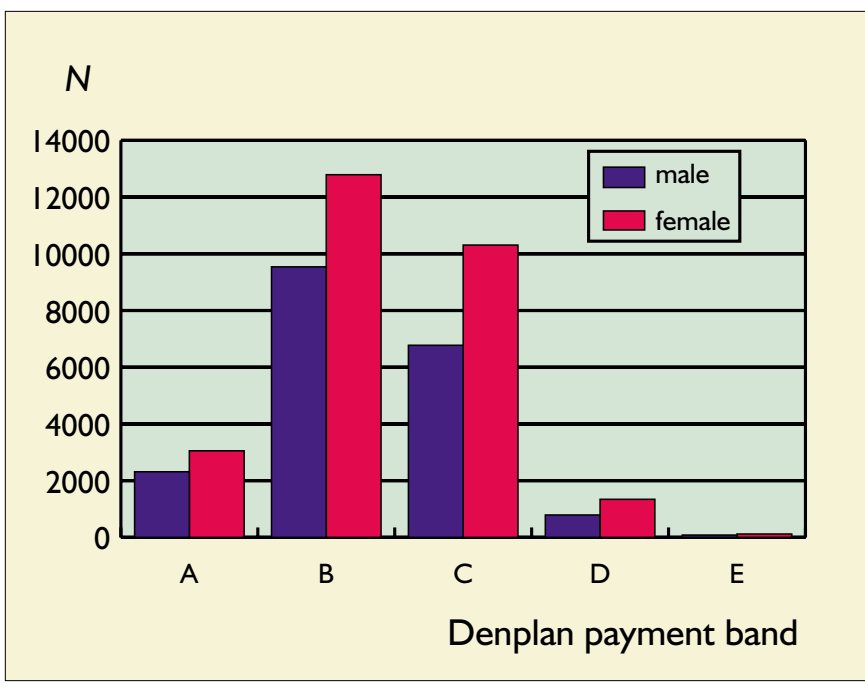

Fig. 2 Frequency distribution of Denplan capitation patients by payment banding and gender

their use of the service. A market penetration ranking report was produced by a spreadsheet analysis in Microsoft Excel. This analysis starts with counts of the number of subjects registered with Denplan and the total population resident in the EDs (derived from Census denominators) making up each Target Market. This was expressed as a rate per 1000 population and the Target Markets were ranked according to this rate. The individual Target Market rates were compared with the average rate for the table as a whole and this comparison was expressed in index form ie with the overall mean set to 100. The ranking 'penetration' at Target Market level can be examined by comparing the cumulative percentage of registered subjects using the service with the corresponding cumulative percentage of the population. A Lorenz curve was plotted to graphically represent the output of the market penetration analysis. The curve is based on the cumulative percentage of Denplan patients in each Target Market that corresponds to the cumulative percentage of the total population in each Target Market. The Lorenz curve provides a measure of the effectiveness of Super Profiles Target Markets in isolating high rates of Denplan registration in a relatively small number of area types. The effectiveness score produced is calculated from the area between the curve and the diagonal. A diagonal plot 
Table I Super Profile Target Market Penetration Ranking Report of patients registered with Denplan in the North West Region

\begin{tabular}{|c|c|c|c|c|c|c|c|c|}
\hline $\begin{array}{l}\text { Target } \\
\text { Market }\end{array}$ & $\begin{array}{l}\text { NW Region } \\
\text { total population }\end{array}$ & $\begin{array}{c}\text { N Denplan } \\
\text { patients }\end{array}$ & $\begin{array}{l}\text { Patients } \\
/ 1000\end{array}$ & Index & $\begin{array}{c}\% \text { NW Region } \\
\text { total } \\
\text { population }\end{array}$ & $\begin{array}{c}\% \\
\text { Patients }\end{array}$ & $\begin{array}{l}\text { Cumulative } \\
\% \text { total } \\
\text { Population }\end{array}$ & $\begin{array}{l}\text { Cumulative } \\
\% \text { patients }\end{array}$ \\
\hline FI9 & 56235 & 1322 & 23.5 & 317 & 0.9 & 2.8 & 0.9 & 2.8 \\
\hline $\mathrm{F} 25$ & 12925 & 270 & 20.9 & 282 & 0.2 & 0.6 & I.I & 3.4 \\
\hline $\mathrm{B} 18$ & 68804 & 1329 & 19.3 & 260 & I.I & 2.8 & 2.2 & 6.2 \\
\hline $\mathrm{B} 17$ & 58975 & 1070 & 18.1 & 245 & 0.9 & 2.3 & 3.1 & 8.5 \\
\hline $\mathrm{A} 0 \mathrm{I}$ & 119312 & 2059 & 17.3 & 233 & 1.9 & 4.4 & 5.0 & 12.8 \\
\hline A04 & 329923 & 5167 & 15.7 & 211 & 5.2 & 11.0 & 10.2 & 23.8 \\
\hline $\mathrm{B} 12$ & |3753| & 2028 & 14.7 & 199 & 2.2 & 4.3 & 12.3 & 28.1 \\
\hline A06 & I42843 & 2034 & 14.2 & 192 & 2.3 & 4.3 & 14.6 & 32.4 \\
\hline D02 & 126660 & 1749 & 13.8 & 186 & 2.0 & 3.7 & 16.6 & 36.2 \\
\hline B05 & 46549 & 601 & 12.9 & 174 & 0.7 & 1.3 & 17.3 & 37.4 \\
\hline B07 & 229520 & 2762 & 12.0 & 162 & 3.6 & 5.9 & 20.9 & 43.3 \\
\hline $\mathrm{Cl} 4$ & 212206 & 2195 & 10.3 & 139 & 3.3 & 4.7 & 24.3 & 48.0 \\
\hline D09 & 3603 & 37 & 10.3 & 138 & 0.1 & 0.1 & 24.3 & 48.0 \\
\hline D08 & 88180 & 895 & 10.1 & 137 & 1.4 & 1.9 & 25.7 & 49.9 \\
\hline $\mathrm{Cl} 6$ & |3346| & 1337 & 10.0 & 135 & 2.1 & 2.8 & 27.8 & 52.8 \\
\hline G22 & 101316 & 984 & 9.7 & 131 & 1.6 & 2.1 & 29.4 & 54.9 \\
\hline $\mathrm{Cll}$ & 586228 & 5347 & 9.1 & 123 & 9.2 & 11.4 & 38.7 & 66.2 \\
\hline $\mathrm{H} 24$ & 360337 & 2850 & 7.9 & 107 & 5.7 & 6.1 & 44.3 & 72.3 \\
\hline G23 & 83609 & 594 & 7.1 & 96 & 1.3 & 1.3 & 45.6 & 73.5 \\
\hline DI5 & 226386 & 1533 & 6.8 & 91 & 3.6 & 3.3 & 49.2 & 76.8 \\
\hline E20 & 25799 & 168 & 6.5 & 88 & 0.4 & 0.4 & 49.6 & 77.1 \\
\hline DI3 & 98267 & 634 & 6.5 & 87 & 1.6 & 1.4 & 51.2 & 78.5 \\
\hline G26 & 135764 & 808 & 6.0 & 80 & 2.1 & 1.7 & 53.3 & 80.2 \\
\hline G32 & 56348 & 325 & 5.8 & 78 & 0.9 & 0.7 & 54.2 & 80.9 \\
\hline E30 & 13604 & 76 & 5.6 & 75 & 0.2 & 0.2 & 54.4 & 81.0 \\
\hline 137 & 300849 & 1672 & 5.6 & 75 & 4.7 & 3.6 & 59.1 & 84.6 \\
\hline EIO & 22649 & 125 & 5.5 & 74 & 0.4 & 0.3 & 59.5 & 84.9 \\
\hline D27 & $47 I 067$ & 2313 & 4.9 & 66 & 7.4 & 4.9 & 66.9 & 89.8 \\
\hline H33 & 252914 & 1175 & 4.6 & 63 & 4.0 & 2.5 & 70.9 & 92.3 \\
\hline D28 & 105834 & 453 & 4.3 & 58 & 1.7 & 1.0 & 72.6 & 93.2 \\
\hline E2I & 72076 & 302 & 4.2 & 56 & I.I & 0.6 & 73.7 & 93.9 \\
\hline $\mathrm{H} 36$ & 259564 & 739 & 2.8 & 38 & 4.1 & 1.6 & 77.8 & 95.4 \\
\hline E03 & 9704 & 23 & 2.4 & 32 & 0.2 & 0.1 & 77.9 & 95.5 \\
\hline 135 & 41780 & 97 & 2.3 & 31 & 0.7 & 0.2 & 78.6 & 95.7 \\
\hline J31 & 36644 & 81 & 2.2 & 30 & 0.6 & 0.2 & 79.2 & 95.9 \\
\hline 134 & 290102 & 628 & 2.2 & 29 & 4.6 & 1.3 & 83.7 & 97.2 \\
\hline E29 & 157188 & 272 & 1.7 & 23 & 2.5 & 0.6 & 86.2 & 97.8 \\
\hline J38 & 583896 & 795 & 1.4 & 18 & 9.2 & 1.7 & 95.4 & 99.5 \\
\hline j40 & 153690 & 155 & 1.0 & 14 & 2.4 & 0.3 & 97.8 & 99.8 \\
\hline j39 & 138124 & 104 & 0.8 & 10 & 2.2 & 0.2 & 100.0 & 100.0 \\
\hline Totals & 6350466 & 47108 & & & & & & \\
\hline
\end{tabular}

of 45 degrees would indicate an even distribution of Denplan registration between the Target Markets, that is the proportion of the patient population in any Target Market would equal the population proportion.

Following the market penetration analysis the EDs of the six top ranked Target Markets in the North West Region were identified and mapped out across the Region using Map Info GIS. Finally, the number and percentage of EDs in the six top ranked Target Markets were identified for each health authority in the Region.

\section{Results}

Some 47,106 patients were registered with Denplan and resident in the North West Region. Only $2.4 \%$ of records could not be georeferenced from the postcode. The age/gender distribution is presented in Figure 1. In all but one 5-year age band (16-20-year-olds) female patients were in the majority and $58.6 \%$ of the total patient population was female. Only 34 patients appeared in the $0-5$ year age band, indeed children under 16 made up only $2 \%(N=769)$ of the total patient population. Some $40.5 \%$ of the patient population were concentrated into the $40-55$ age group. Figure 2 shows the distribution of the population according to the payment banding structure. Nearly $50 \%(22,329)$ of patients were allocated to the B banding and under $0.5 \%$ of patients $(N=199)$ were categorised into the highest (E) payment band.

Table 1 presents the results of the market penetration analysis. Around a half (49.9\%) of Denplan patients were present in just over a quarter $(25.7 \%)$ of the total population of the North West Region. The Target Markets at the top of the ranking were more affluent in nature, with a strong rural element and an older demographic profile as part of their descriptive titles. For example patients living in F19 Prosperous Farming Communities, F25 Smallholders and Rural Workers Mainly in Scotland, B18 Affluent Ageing Couples in Rural Areas, B17 Comfortably Well-Off Older Owner Occupiers, A01 Very High Income Professionals in Exclusive Areas, and A04 Mature Families with Large Detached Properties in 'Stockbroker Belts' made up more than $10 \%$ of the Denplan patient population. At the bottom of the ranking deprived area types with young demographic profiles predominated. For example the bottom three area types were: J39 Young Families, Many Single Parent. High Unemployment; J40 Young Singles and Pensioners in Council Flats, High 


\section{$\begin{array}{r}\text { RESEARCH } \\ \text { demographics } \\ \hline\end{array}$}

Table 2 North West Region: total number of ED and the ED making up the top six ranking Target Markets - $\mathbf{N}$ and as a percentage of all ED by Health Authority

\begin{tabular}{|c|c|c|c|}
\hline \multirow[t]{2}{*}{ Health Authority } & \multirow{2}{*}{$\begin{array}{l}\text { Total } \\
\text { number of } \\
\text { ED }\end{array}$} & \multicolumn{2}{|c|}{$\begin{array}{c}\text { ED of the top six ranking } \\
\text { Target Markets }\end{array}$} \\
\hline & & & $\%$ \\
\hline Bury \& Rochdale & 764 & 62 & 8.1 \\
\hline East Lancashire & 1,110 & 110 & 9.9 \\
\hline Liverpool & 976 & 36 & 3.7 \\
\hline Manchester & 897 & 21 & 2.3 \\
\hline Morecambe Bay & 694 & 161 & 23.2 \\
\hline North Cheshire & 606 & 46 & 7.6 \\
\hline North West Lancashire & 976 & 104 & 10.7 \\
\hline Salford \& Trafford & 915 & 75 & 8.2 \\
\hline Sefton & 576 & 63 & 10.9 \\
\hline South Cheshire & $\mathrm{I}, 544$ & 471 & 30.5 \\
\hline South Lancashire & 597 & 107 & 17.9 \\
\hline St Helens \& Knowlsley & 618 & 27 & 4.4 \\
\hline Stockport & 578 & 110 & 19.0 \\
\hline West Pennine & 881 & 31 & 3.5 \\
\hline Wigan \& Bolton & 1,124 & 65 & 5.8 \\
\hline Wirral & 703 & 83 & 11.8 \\
\hline
\end{tabular}

Unemployment; and J38 Blue Collar Young Families in Council Properties, High Unemployment.

The Lorenz curve produced from the outputs of the penetration ranking is presented in Figure 3. The area underneath the curve represents the effectiveness of the Super Profiles Target Markets in identifying areas with high levels of Denplan registration. The Lorenz curve showed that Super Profiles at Target Market level had an effectiveness of $37.9 \%$ in segmenting the population of the North West Region according to Denplan registration status.

Figure 4 depicts the location of EDs in the North West Region in the six top ranked Target Markets of the penetration analysis, superimposed on the administrative geography of the health authorities. The major conurbations of Liverpool and Manchester are largely blank, as are the cotton towns of north and east Lancashire. The rural green EDs are situated predominantly in the north of the Region (south of the Lake District) and in southwest Cheshire. The blue, very affluent EDs are concentrated in northeast Cheshire in the stockbroker belt of Manchester.

Table 2 shows the number of EDs in the six top ranked Target Markets in each of the health authorities in the North West Region, and as a percentage of all EDs in each health authority. In South Cheshire Health Authority nearly one third (30.5\%) of the district was composed of EDs which were in the six top ranked Target Markets. Morecambe Bay Health Authority was made up of $23.2 \%$ of these EDs, compared with $2.3 \%$ of Manchester Health Authority.

\section{Discussion}

Only $0.07 \%$ of the 6.3 million population of the North West Region were registered with Denplan. This compares with $60.9 \%$ of the Region's population who were registered with a NHS dentist.

The age/gender distribution presented in Figure 1 provides an interesting insight into the users of the service. More women than men were registered with Denplan (females 58.6\%, males 41.4\%). This result was not surprising, research has consistently showed that for all age groups, women were more likely to use dental services than men. ${ }^{6,10}$ This has been ascribed to social pressures on women to showed a positive self-image.

The age profile of the Denplan patient population was very different from that registered with GDS services. A very small proportion of patients were of school age, and the age bands with the most patients were between 41 and 55 years, whereas the peak ages for the population registered with a GDS dentist are in the 3-5, 6-12 and 13-18-year-old age cohorts used by the Dental Practice Board. ${ }^{11}$ The view that the majority of GDPs still offer NHS care to children, even though they may offer care to their adult patients under independent funding arrangements, ${ }^{12}$ would seem to concur with the findings of this study. One possible explanation for this phenomenon is that when a practice intends to convert to independent sector care, as many families as possible attending the practice need to be retained. As there are few problems for children in the North West Region in gaining access to NHS care, GDPs are unlikely to insist on independent sector care for their child patients under these circumstances.
Fig. 3 Lorenz curve: cumulative percent of Denplan registered patients in Super Profiles Target Markets according to a penetration ranking report plotted against the cumulative per cent of the population of the North West Region in the corresponding Target Markets
Cumulative percent of

Denplan patients (\%)

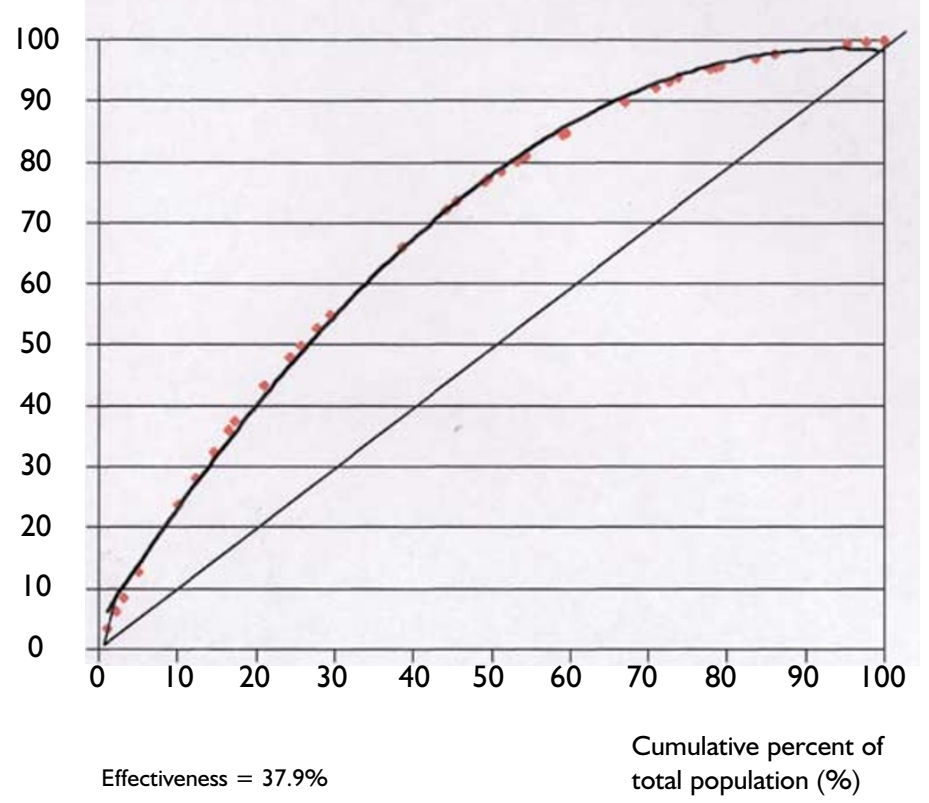




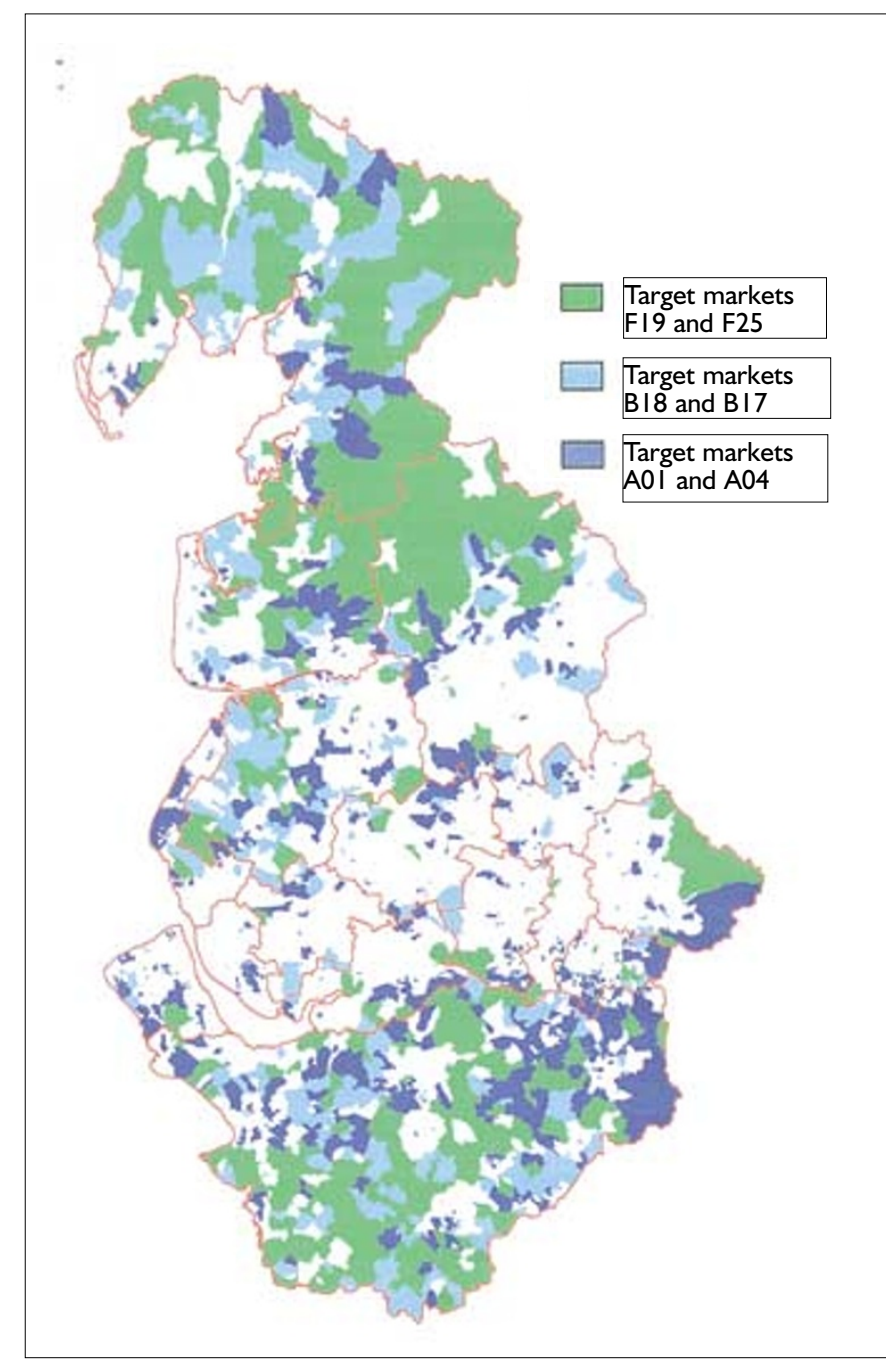

Fig. 4 Map of the North West Region identifying the location of enumeration districts in the six topmost ranked Target Markets of a penetration ranking report of patients registered with Denplan

The greatest number of patients were categorised into pay band B. A very small proportion of the total population were in bands D and E. Dental ill-health is closely associated with deprivation ${ }^{10}$ and preventive behaviour aimed at reducing the risk of disease is more prevalent in more affluent populations. ${ }^{13}$ So it is not surprising given the socio-economic make-up of the Denplan patient population that the majority of patients fell into the low risk pay bands.

\section{Geodemographic analysis}

The penetration ranking showed that the rates per 1,000 population were small, ranging from 23.5 patients to 0.8 per 1,000 population. This is a reflection of the total dental care provision in the North West Region and no doubt the rates would be higher in other parts of the country where independent sector care has been more widely embraced.

The penetration ranking showed a stark contrast in the types of area appearing at the top and bottom of the ranking, with affluent area types dominating the top of the ranking and deprived types at the bottom. Indeed it was surprising to find that over 1,000 Denplan patients lived in the most deprived Target Markets. This is perhaps explained by the nature of area measures of socio-economic status. Although Super Profiles is based on very small areas (around 120 households), the populations of these very small areas are not completely homogeneous. Therefore the stereotypical descriptors are not an accurate reflection of the personal circumstances and therefore the health-related behaviour of every individual who lives in a disadvantaged area type.

Area types with more mature resident populations were evident at the top of the ranking and those with younger populations at the bottom of the ranking. This is reflected in the findings of the age/gender distribution of the patient population. The appearance of the two rural Target Markets at the top of the ranking was interesting. Rural areas tend to have fewer dental practices and therefore there is possibly less choice of NHS alternatives for the local population. This is probably one factor explaining the comparatively poor market penetration in many of the urban areas of the North West Region where access to NHS care is less of a problem.

The map produced in Figure 4, and also the results summarised in Table 2 show that the EDs in the six top ranked Target Market area types are concentrated in the north and south of the Region. This map will indicate to GDPs if their practice is situated in an area where the 'high response' area types predominate. It could be hypothesised that if a practice is located in an area with a large number of these area types, the greater is the potential to attract patients willing to register with Denplan. However, patient mobility must be considered when examining uptake of dental care, and thriving Denplan practices are not solely confined to these areas. Given the affluent nature of Denplan patients, many may be prepared to travel to access their care or register with a practice near their place of work. Therefore a dentist must look at the geodemographic profile of his or her patient population as well as that of his/her potential catchment area population.

This information will also be of interest to NHS planners, particularly now that access to NHS dentistry is a priority. However, access to this information is at the discretion of the companies operating in the independent sector. It must also be remembered that it is unlikely that a complete population account of care provided by the independent sector is achievable, as the majority of this care is provided on a private fee-for-item basis. This information is unavailable as it relates to a private matter between the individual dentist and his or her patients. It may be a more realistic option for the NHS to use the techniques used in this study to examine registration patterns in the GDS, or perhaps to provide a breakdown of the population attending the new 'Dental Access Centres'.

The penetration ranking report showed that about $50 \%$ of Denplan patients were confined to a quarter of the North West Region's population. The classification was demonstrably more effective at confining those registered with Denplan to a small number of area types (as shown by the effectiveness score of the Lorenz curve in Figure 3), than it was in segmenting child populations according to caries prevalence ${ }^{14}$ or GDS registration with a dentist. ${ }^{15}$ This may reflect the type of service under study as geodemographic classifications have been principally designed for marketing purposes for business rather than healthcare needs assessment tools. It may also be a function of the Denplan registration rates, as they are much smaller than caries prevalence or GDS registration rates in the child population. The effectiveness of the classification will be limited by the fact that Super Profiles is a national classification and therefore not specific to service or to the regional population under study. It must also be remembered that local overlying geographical factors plus the availability of NHS services, uncontrolled for in this analysis, would also influence uptake of the service. Therefore the techniques used in this study will show an association between uptake of independent dental care according to the make up of populations at a small area level. These methodologies cannot demonstrate cause and effect and identify why people use independent sector dental care.

\section{Conclusion}

The population using this service in the North West Region tend to be from more mature, rural and affluent populations. The Super 
Profiles classification was moderately successful in segmenting the population of the North West Region according to their Denplan registration status. This study provides a first look at the population accessing primary dental care in the capitation market in the North West Region. There are multiple and interconnected influences affecting uptake of primary dental care under the Denplan brand name. The reasons for the findings can only be speculated upon and points to a need for qualitative research to understand the reasons why patients seek care in the independent sector.

1 Department of Health. The Dental Contract detailed guidance Annex to FPN 524. London: HMSO, 1990.

2 Kravitz A, Tidman S. General Dental Practice in the UK. Primary Health Care Management 1993: 3; 2-4.

3 Denplan Carter research image tracking survey of consumers. Winchester: Denplan, 1996.

4 6, P, Jupp B, Bentley T. Open wide: futures for Dentistry in 2010. London: Demos, 1996.

5 Tickle M, Jenner A M. Allocating responsibilities between dental care providers. In Rothwell P S (ed) Pathways in Practice. Vol 2. London: Faculty of General Dental Practitioners Royal College of Surgeons, 1997.

6 Locker D. An introduction to behavioural science \& dentistry. London:
Routledge, 1989

7 Brown P J B. Exploring geodemographics. pp221-258 In I Masser, M Blakemore (eds) Handing Geographical Information: Methodology and Potential Applications. London: Longman, 1991.

8 Batey P W J, Brown P J B. From human ecology to customer targeting: the evolution of geodemographics. In R Longley, G Clarke (eds) GIS for business and service planning. Cambridge: Person, 1995.

9 Brown P J B, Batey P W J. Characteristics of Super Profiles Lifestyles and Target Markets: Index tables, pen pictures and geographical distribution. Super Profile Technical Note 2. Liverpool University: URPERRL, 1994.

10 Todd J E, Lader D. Adult Dental Health 1988 United Kingdom. London: HMSO, 1991.

11 Dental Practice Board. GDS quarterly statistics Registrations: OctoberDecember 1997 England and Wales. Eastbourne: DPB, 1998.

12 O'Brian M. Children's Dental Health in the United Kingdom 1993. London: HMSO, 1994.

13 Locker D, Payne B, Ford J. Area variations in health behaviours. Can J Public Health 1996: 87; 125-129.

14 Tickle M, Brown P J B, Blinkhorn A S B, Jenner A M. Comparing the ability of different area measures of socio-economic status to segment a population according to caries prevalence. Community Dent Health (in press).

15 Tickle M. Small area oral health care needs assessment. $\mathrm{PhD}$ Thesis University of Manchester, 1999. 